\title{
Theoretical and Voltammetric Studies of 5-Nitro-heterocyclic Derivatives with Potential Trypanocidal Activities
}

\author{
Fávero R. Paula, ${ }^{*, a, d, \#}$ Gustavo H. G. Trossini, ${ }^{b}$ Elizabeth I. Ferreira, ${ }^{b}$ \\ Silvia H. P. Serrano, ${ }^{c}$ Carla M. S. Menezes ${ }^{b}$ and Leoberto C. Tavares ${ }^{a}$ \\ ${ }^{a}$ Department of Biochemical-Pharmaceutical Technology, ${ }^{b}$ Department of Pharmacy, Faculty of \\ Pharmaceutical Sciences, University of São Paulo, 05508-900 São Paulo-SP, Brazil \\ 'Institute of Chemistry, University of São Paulo, 05508-900 São Paulo-SP, Brazil \\ ${ }^{d}$ Department of Pharmacy, State University of West-Centre of Paraná, \\ 85040-080 Guarapuava-PR, Brazil
}

\begin{abstract}
Neste trabalho, uma série de compostos nitro-heterocíclicos foi submetida a estudos químicoquânticos e de voltametria cíclica com a finalidade de determinar as propriedades físico-químicas que exercem influência sobre o potencial redox do grupo nitro. A otimização de estrutura, as propriedades e os mapas de superfícies estereoeletrônicas foram calculadas utilizando o método semi-empírico AM1. O potencial redox dos compostos, $\mathrm{Ar}-\mathrm{NO}_{2} / \mathrm{Ar}_{-} \mathrm{NO}_{2}^{--}$, foi determinado em meio aprótico (DMSO e eletrólito de suporte $\mathrm{Bu}_{4} \mathrm{NH}_{4} \mathrm{BF}_{4} 0,1 \mathrm{~mol} \mathrm{~L}^{-1}$ ), com o uso de eletrodos de trabalho de carbono vítreo, eletrodo auxiliar de fio de platina e eletrodo de referência de $\mathrm{Ag} / \mathrm{AgCl}$. A investigação dos confôrmeros de menor energia mínima demonstrou a ocorrência de quebra de planaridade estrutural entre o nitrogênio hidrazínico e o resíduo benzamídico. Não foi observada a ocorrência de correlação, avaliada através da análise de regressão de PLS, entre as propriedades estereoeletrônicas e o potencial redox, resultado, provavelmente, de quebra da estrutura co-planar no grupo de moléculas estudadas.
\end{abstract}

Stereoelectronic properties of nitro-heterocyclic bioisosteric congeners were investigated using theory-level quantum chemistry and cyclic voltammetry with the goal of determining physico-chemical properties that affect the redox potential of the nitro group. Molecular geometry, physicochemical properties and stereoelectronic surfaces, such as molecular electrostatic potential, and HOMO and LUMO orbitalar distributions, were calculated using the AM1 semiempirical method. The redox potential of nitro-heterocyclic compounds, which corresponds to the ( $\left.\mathrm{Ar}-\mathrm{NO}_{2} / \mathrm{Ar}^{-\mathrm{NO}_{2}^{--}}\right)$ redox couple, was measured in aprotic media (DMSO and $0.1 \mathrm{~mol} \mathrm{~L}^{-1} \mathrm{Bu}_{4} \mathrm{NH}_{4} \mathrm{BF}_{4}$ ) using glassy carbon as working electrode, $\mathrm{Pt}$ wire, $\mathrm{Ag} / \mathrm{AgCl}, \mathrm{KCl}(\mathrm{sat})$ as counter and reference electrodes, respectively. Analysis of minimal energy conformers of all derivatives indicated a break in structural planarity located between the hydrazine nitrogen and benzamide moiety. No statistical correlation was obtained using the PLS regression method, taking in account all physicochemical properties and the redox potential, which might result from the lack of coplanarity effect in the molecular structure of the compounds.

Keywords: 5-nitro-heterocyclic, stereoelectronic properties, redox potential

\section{Introduction}

Chagas' disease affects millions of people all around Latin America. ${ }^{1}$ Therapeutic agents used in the disease treatment are usually ineffective during the chronic phase of injury and promote serious side effects to the infected

\footnotetext{
*e-mail: faverorp@usp.br
}

patients. ${ }^{2}$ Thus, the development of new anti-Trypanosoma cruzi agents is an urgent necessity. Several studies describe the interesting activities of some 5-nitro-heterocyclic compounds against Trypanosoma cruzi..$^{3-7}$

Some nitrocompounds, as nifuroxazide, nifuroxime or nifurprazine, act as subversive substrates for trypanothione reductase (TR) of T. cruzi, and also inhibit the enzymatic reduction of trypanothione disulphide (the enzyme's 
physiological substrate). ${ }^{7,8}$ These compounds suffer bioreduction by reductases, such as TR, and the generated nitro radical anion reacts with the oxygen in the futile redox cycling, producing the reactive superoxide and hydroxyl radicals which are poisonous to the parasite. ${ }^{9,10}$ Comprehension of the nitro group reduction process, as well as, the experimental determination of the redox potential $\left(\mathrm{E}^{\circ}\right)$ are important paths to provide better understanding about the drug action mechanisms and, principally, how the $\mathrm{E}^{\mathrm{o}}$ values are related with the therapeutic activity of the nitro compounds.

Nifuroxazide, 5-nitro-2-furfurylidene 4-hidroxybenzhydrazide, is a known antimicrobial therapeutic agent with anti-T. cruzi activity. ${ }^{6}$ Taking into account the prevalence of Chagas' disease and considering that bioisosteric analogs, with similar structures and electronic properties, also present related biological activities, a series of 5-nitro-2-furfurylidene benzhydrazides and 5-nitro-2-thiophylidene benzhydrazides analogs of nifuroxazide was synthesized. ${ }^{11-13}$ Some of these compounds showed antimicrobial activity ${ }^{11-13}$ and good activity when assayed against epimastigote forms of $\mathrm{Y}$ strain of $T$. cruzi. ${ }^{14}$ Both nitro-heterocyclic families contain several functional groups attached to a benzhydrazide group, and all of them present a nitro group attached to the carbon 5 of two isosteric heterocyclic five-membered rings, furfurylidene and thiophylidene, structural feature required for biological activity.

Understand the main structural requirements and the physicochemical factors which may influence the reductive system is another way to understand the free radical generation from nitro compounds and their anti-parasitic activity. Moreover, several studies use quantum chemical methods to determine theoretical physicochemical properties with the aim to correlate these effects to electrochemical data. ${ }^{4,15-17}$ Likewise, the conformational analysis of the flexible side chain bound to the nitro-heterocyclic group has received growing interest in some reports, since these molecules present different conformations and geometric features that might influence the redox system and also the drug-biological target interaction. ${ }^{4,16-19}$

In molecular modeling studies HOMO and LUMO distributions, electronic density distribution, and energy eigenvalues in solvate and gaseous phases, are some relevant physicochemical characteristics usually determined, which are used to analyze the influence of mesomeric effects on the molecular structure. Among these properties, the molecular electrostatic potential (MEP) map is a powerful tool for understanding the influence of electronic effects and molecular fields on the molecular behavior of the compounds. ${ }^{20-22}$ For this purpose, MEP calculation was used to compare the series of both nitro-heterocyclic congeners to verify whether there is a difference in the resonance effect among the series of compounds.

The present study describes the determination of minima local energy, geometry optimization, conformational analysis, single point calculation and electronic surfaces (MEPs and HOMO and LUMO distributions) using quantum chemistry methods for eight 5-nitro-2-thiophylidene benzhydrazides and eight 5-nitro2-furfurylidene benzhydrazides, Figure 1. Additionally, the redox potentials of the nitro-heterocyclic compounds were determined using cyclic voltammetry, followed by an evaluation of the influence of quantum chemistry properties on the nitro group redox process. This information might be used to understand the nitro reduction behavior of the bioisosteric analogs of nifuroxazide, which had been proved to be a trypanocidal compound.

\section{Experimental}

\section{Nitro-heterocyclic compounds}

All the compounds used in this work, eight 5-nitro2-thiophylidene benzhydrazides and eight 5-nitro-2furfurylidene benzhydrazides, were designed using the isosteric substitution aiming to obtain the variation on the structural and electronic properties. They were synthesized and characterized in the Laboratory of Development and Design of Drugs, University of Sao Paulo (Sao PauloBrazil). ${ }^{11-13}$ The basic chemical structures are shown in Figure 1, and all molecules employed in this work are shown in Table 1. In addition to these compounds two 5-nitro-2-thiophylidene derivatives (not yet synthesized) which represent, a fluoro-vinyl or an ethyl group substitution on the benzene ring, respectively, were also used. The last compounds were employed to investigate whether the benzene group interferes in the coplanarity effect of chemical structures.
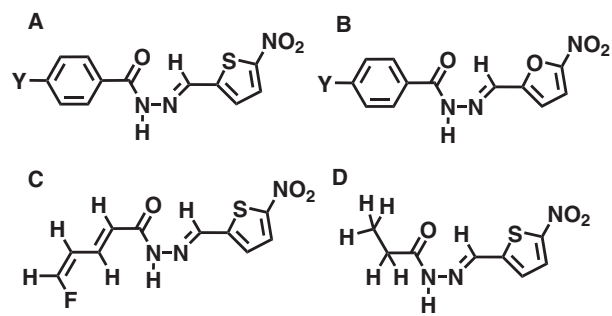

Figure 1. Chemical structure of 5-nitro-2-thiophylidene 4-Y-benzhydrazides and 5-nitro-2-furfurylidene 4-Y-benzhydrazides. (A) 5-nitro-2-thiophylidene benzhydrazides, (B) 5-nitro-2-furfuryliden benzhydrazides, (C) 5-nitro-2-thiophylidene 4-fluorodivinylhydrazide, (D) 5-nitro-2-thiophylidene 4-ethylhydrazide. 


\section{Computational Details}

The computational analyses were performed using Spartan 04 version $116.2^{\mathrm{TM}}$ for Linux (Wavefunction, Inc., USA $)^{23}$ and all initial structures were built using atoms and structural fragments from its molecular editor. Geometry optimization was carried out using the semi empirical AM1 Hamiltonian method. ${ }^{24}$ Systematic conformational search for nitro-heterocyclic compounds was performed after carrying out the full geometry optimization. The torsion angle increment was set to $30^{\circ}$ in the range $0-360^{\circ}$ in $\theta_{1}-\theta_{5}$ and $\theta_{6}$, depending on the substituted group attached to the para position of benzhydrazide, Figure 2. The lowestenergy conformation of each molecule was identified and obtained in the solvate, by continuum Born derivative SM5.4 model, and gaseous phase using semiempirical AM1 calculation.

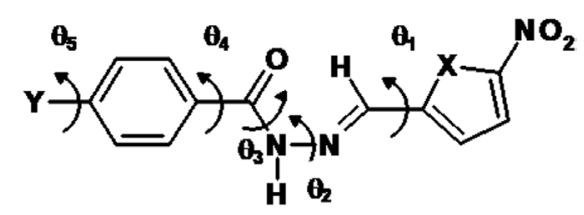

Figure 2. Torsion angles of 5-nitro-heterocyclic compounds used in conformational analysis, where the $\mathrm{X}$ might be $\mathrm{S}$ (thiophylidene) or $\mathrm{O}$ (furfurylidene) derivatives and $\mathrm{Y}$ is the substituent attached to the benzene ring.

After the conclusion of the conformational search, the minimal energy conformations, obtained in the gaseous phase, were chosen for subsequent investigation. All the molecules with the most stable conformations were submitted to single point calculations and, relevant physicochemical properties and molecular surfaces such as HOMO, LUMO, and Electrostatic Potential (MEPs) maps were obtained. Geometric properties, such as molecular volume and interatomic distance ( ) and electronic properties, such as energy of formation $\left(\Delta \mathrm{H}_{\mathrm{f}}\right)$, energy of highest occupied molecular orbital $\left(\mathrm{E}_{\text {номо }}\right)$, energy of lowest unoccupied molecular orbital $\left(\mathrm{E}_{\mathrm{LUMO}}\right)$, global hardness $(\eta)$, and electrostatic potential charges $(Q)$ eigenvalues were also determined.

MEP isoenergy contours were generated in the range of 35 to $-60 \mathrm{kcal} \mathrm{mol}^{-1}$. The isosurface of MEPs were obtained at the van der Waals contact surface, which represents the potentials superimposed onto a surface of constant electron density $\left(0.002 \mathrm{e} \mathrm{au}^{-3}\right)$. The color intensity showed the lower or higher positive or negative electrostatic regions of the molecule. All color-coded surfaces obtained from these calculations provided a measure of the overall size of the molecular fragment and the location of positive, characterized by blue, and negative, by green (less negative) and red (more intensely negative), electrostatic potentials. HOMO and LUMO isosurfaces were calculated at $0.0032 \mathrm{au}^{2}$. The constants used in these isosurface calculations were the default parameters in Spartan software. Atomic charges were derived from electrostatic potentials, which model is based on the calculation of a punctual atomic charge defined around the molecules. ${ }^{25-27}$ These charges are relevant for determining which region of the molecules is more reactive and might also be important for understanding the interaction between the drug and the biological target.

Nifuroxazide was chosen as a template of representative nitro compounds, aiming to corroborate the chemical structure determined through the AM1 method. This compound was submitted to geometry optimization, conformational analysis, and single point calculations using the $a b$ initio Hartree-Fock 6-31G* theory level. This calculation was started from the lowest energy nitro compound conformer and performed by the AM1 method.

\section{Voltammetric assay}

Voltammetric experiments were recorded using an Autolab PGSTAT20 potentiostat/galvanostat, running with the GPES 4.9 software from Eco-Chimie, Utrecht, Netherlands, coupled with a $10 \mathrm{~mL}$ cell with three electrodes, glassy carbon (GCE) as working electrode, and $\mathrm{Ag} / \mathrm{AgCl}, \mathrm{KCl}_{\text {(sat) }}$ and $\mathrm{Pt}$ as reference and auxiliary electrodes, respectively. Before each measurement the GCE was softly polished in a sandpaper 1,200 followed by polishing with a 0.1 and $0.3 \mu \mathrm{m}$ diamond suspension using felt as a supporting cleaning for the GC working electrode. The cyclic voltammograms were obtained in dimethylsulfoxide containing $0.1 \mathrm{~mol} \mathrm{~L}^{-1} \mathrm{Bu}_{4} \mathrm{NH}_{4} \mathrm{BF}_{4}$ as supporting electrolyte and $5.0 \times 10^{-4} \mathrm{~mol} \mathrm{~L}^{-1}$ of each nitro compound. All measurements were performed in the absence of oxygen. The solutions were deoxygenated by nitrogen flow for $30 \mathrm{~min}$ and the optimized experimental conditions were: $-0.15 \leq \mathrm{E}_{\text {applied }} \leq-1.0 \mathrm{~V}$ and scan rate of $100 \mathrm{mV} \mathrm{s}^{-1}$. All reagents were of analytical grade.

\section{Evaluation of influence of physicochemical properties on redox potential}

To evaluate the influence of physicochemical properties on the redox potential the partial least squares (PLS) regression method was used employing the Minitab 4.0 Statistical program. The models obtained in this analysis allow the determination of which physicochemical properties might be exerting an influence on the nitro compound redox potential. 


\section{Results and Discussion}

\section{Nitro compounds}

An essential requisite for the promotion of biological activity in the nitro-heterocyclic compounds has been identified as the bioreduction of the nitro group and the study of physicochemical properties involved in this process. ${ }^{9,10}$ Since eight of the considered compounds showed activity anti-T. cruzi, the evaluation of the redox potential, and other properties, which can influence this process, are important to understand the nitro bioreduction, essential process to anti-T. cruzi activity. The information obtained might be used as an indirect pathway to propose new bioactive nitro compounds.

\section{Molecular modeling and conformational analysis}

The first step after building the compounds' structures was to carry out the geometry optimization using the semiempirical AM1 Hamiltonian method. The optimized structures for both classes of 5-nitro-heterocyclic derivatives were submitted to conformational analysis followed by single point calculations, the determination of physicochemical properties and molecular surfaces.

Systematic conformational analyses were performed to investigate the conformational behavior, aiming to obtain the minimal global energy conformer of each compound analyzed. These studies may indicate which structure is more stable in the solvate or gaseous phase when all set of structures is compared; moreover, conformational changes are important for the study of the influence of chemical structure on the redox system, and to evaluate the increase, decrease or even loss of anti-T. cruzi activity. Hence, the lowest energy conformation for all bioisosteric compounds in both the solvate and gaseous phases were obtained.

The evaluation of the interaction between the solute and solvent is normally a difficult process. One of the most crucial factors determining the configuration and conformation of chemical structures in biological material is the human body environment. However, some methods such as the self-consistent reaction field (SCRF) or continuum Born derivative SM5.4 model implemented in Spartan software package appear to be a robust tool used to examine the effect of solvent on the molecular geometry. ${ }^{28-30}$ This solvent model is simple to implement and computationally efficient, and allows the determination of the solvation free energies as well as the prediction, in a polar and aqueous media, of the long-range structure and stability interaction trends. In general, the solvation effects are evaluated by more sophisticated calculation methods such as $a b$ initio and density functional levels of theory. ${ }^{21,30}$ Because of this, we are reporting only the preliminary features determined from the conformational search, with the goal of evaluating the influence of solvent on the calculated lowest energy conformers.

To understand the minimum energy conformer models of nitro-heterocyclic derivatives, the 5-nitro-2-furfurylidene benzhydrazide and its thiophylidene isoster were taken as templates for superimposition at the benzhydrazide molecular regions, aiming to do the comparison of the most stable configurations for all compounds studied.

5-Nitro-2-thiophylidene benzhydrazydes, obtained from solvate and gaseous media, presented two different minimal energy conformations. A hydrogen atom attached to the nitrogen of the amidic region in the aliphatic acylhydrazone and hydrogen atoms of the heterocyclic nitro-thiophylidene ring show a translike conformation in the solvate phase and a cis-like conformation in the gaseous phase, Figure 3. 5-Nitro2-furfurylidene benzhydrazide derivatives, obtained in the gaseous and solvate phases, showed a singular conformation. Only the trans-like conformation of the hydrogen atom attached to the nitrogen of the amidic region in the aliphatic acylhydrazone and, hydrogen atoms of the nitro-furfurylidene moiety, were obtained in these calculations. Moreover, when all compounds were placed in superimposed structures, no significant differences $\left(<5.0 \mathrm{kcal} \mathrm{mol}^{-1}\right)$ were observed in the chemical structures orientation. The benzene region fits very well, while the hydrazide 5-nitro-heterocyclic region of the molecule occupies an unlikely position between the nitro-thiophylidene and nitro-furfurylidene rings. These differences in the lowest minimal energy conformations are due to the higher atomic volume of the sulphur in comparison with the oxygen in the nitroheterocyclic rings. This effect, as observed in space filling models (Figure 3), results in steric hindrance between the sulphur and hydrogen atoms of the hydrazide portion of the molecule. Like the lowest minimal energy conformations, the difference of global minimal energy conformation values for gaseous and solvate phases were not significant to each other. The conformational analyses show the occurrence of isoconformers that demonstrate the simultaneous coexistence of different conformers, indicating that any conformation might be used in posterior analyses.

Another relevant feature, concerning the configuration of these classes of derivatives, is the structures obtained from the nifuroxazide crystal. Pniewska and Januchowski, ${ }^{30}$ after crystallization of this compound in dimethylsulfoxide, have determined that the hydrogen atoms of the 5-nitro- 


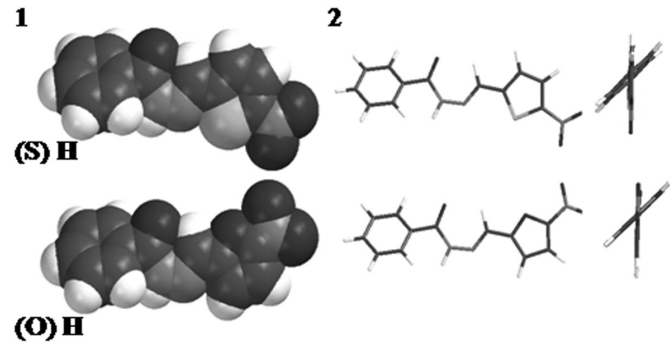

Figure 3. Space filling (1) and tube models (2) demonstrating the front and lateral views of the nitro-heterocyclic global minimal energy conformers calculated by AM1 method. (S) thiophylidene; (O) furfurylidene derivatives.

furfurylidene-2-hydrazide molecular portion are in cis-like configuration. From the conformational analysis carried out for nifuroxazide, however, this cis-like conformer demonstrates an eigenvalue of $5.44 \mathrm{kcal} \mathrm{mol}^{-1}$, higher than the trans-like global minimal energy conformer obtained in the gaseous phase. To corroborate this data, the total energy eigenvalues of two conformers were calculated by geometry optimization using the ab initio $\mathrm{HF} / 6$ $31 \mathrm{G}^{*}$. This procedure confirms that the trans-like global minimal energy conformer shows lower energy eigenvalues $\left(-997.1326 \mathrm{au}^{2}\right)$ compared to that of nifuroxazide obtained from the crystal structure $\left(-997.1248 \mathrm{au}^{2}\right)$. The structure obtained from the gaseous phase provides the same results as those determined by AM1 calculation. Hence, this factor suggests that the conformer obtained in dimethylsulfoxide media might not be the most stable in the phase studied. Another consideration about these results takes into account that the conformer obtained in the gaseous phase is different from that found in dimethylsulfoxide; the incidence of hydrogen bond, due to the strong hydrogen bond-accepting character of the oxygen atom of dimethylsulfoxide, adds a large bulky group of this solvent to a molecule, which changes its conformational properties. Both configurations analyzed above are shown in Figure 4, as hydrogen atoms in configuration trans-like (1) and cis-like (2).

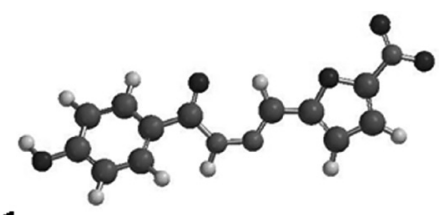

1

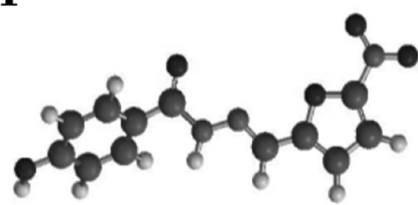

2

Figure 4. Nifuroxazide illustrated as balls and sticks model: (A) Global minimal energy conformer calculated for AM1. Hydrogen atoms in configuration (1) trans-like and (2) cis-like.
As such, the substitution of hydrogen atoms attached at the para position of the benzene ring by functional groups of the studied compounds does not directly affect the structure of the compounds configuration. For the purpose of determination of geometric and electronic features, the conformations obtained from the gaseous phase are taken as a template for single point calculations.

All studied compounds show coplanar geometries from the nitro-heterocyclic moiety to the hydrazide region of molecule, with the broken coplanarity located in the amide group attached at the benzene ring. The analyzed compounds show similar values for the dihedral angle studied, with $\theta 4$, O16-C7-C4-C3 (Table 1), presenting the greater range $\left(35\right.$ to $\left.41^{\circ}\right)$. These results mean that the benzene ring shows deviations of around $40^{\circ}$ out-of-plane for the 5-nitro-heterocyclic-hydrazide region in the molecular structure. The structural break of the coplanar effect in this region of the molecule is in agreement with a previous report for nifuroxazide crystal analysis. ${ }^{31}$ The most relevant dihedral angles are shown in Table 1.

The influence of the benzene group on the breaking of the coplanarity molecular effect was evaluated using two nitro-thiophylidene derivatives (substitution of the ring by divinyl-fluoro and ethyl groups) were designed and built using Spartan software. These compounds present an aliphatic carbonic chain that confers lower molecular volume and steric effect to this molecular region. The presence of the divinyl fluoro or ethyl group in substitution to the benzene ring makes these molecules coplanar and almost coplanar, respectively, with the 5-nitro-thiophylidene 2-hydrazide region. With the ethyl derivative, the first carbon atom suffers some torsion in the bond with the secondary carbon due to the repulsion of the hydrogen atoms attached to this group. These results indicate that the benzene group is responsible for the occurrence of the broken coplanarity structure, which results in the hydrogen repulsion between the amide group and hydrogen atoms attached to the ortho position on the benzene group.

Other important properties determined in this study were the molecular volume and intramolecular distance. These are normally employed to understand the nitroheterocyclic geometric features and the influence of them on anti-T. cruzi activity. No influence of geometric properties was observed among the global minimal energy conformers. As could be expected, as greater the substituent group attached to the para position of the benzene ring of the nitro compounds, as larger the molecular volume, and interatomic distances and extremities determined in these calculations. 


\section{Electronic properties}

In a complementary study, the global minimal energy conformers of molecules obtained in the gaseous phase were extracted from the list of obtained conformers and submitted to single point energy calculations, determination of physicochemical properties, MEPs, and HOMO and LUMO distribution maps. The geometric and structural requirements obtained from single point calculations show the same results as those determined by conformational analyses. The energy of formation $\left(\Delta \mathrm{H}_{\mathrm{f}}\right)$ values of the molecular system fluctuate according to the minor substitution of the hydrogen atom by functional groups at the para position of reference compounds, 5-nitro-2-furfurylidene benzhydrazide and 5-nitro-2-thiophylidene benzhydrazide. All energy of formation values are shown in Table 2 . The trifluoromethyl group attached to the benzene ring of thiophylidene and furfurylidene derivatives shows the eigenvalues to be -90.3166 and $-103.9883 \mathrm{kcal} \mathrm{mol}^{-1}$, respectively, and this result suggests that they may be the most stable compounds present in the gaseous phase in comparison to all the other derivatives. These results, however, need to be confirmed by experimental and other theoretical procedures in order to be directly compared to each other.

The isosurface of MEP for representative members of nitro-heterocyclic compounds, 5-nitro-2-furfurylidene benzhydrazide and 5-nitro-2-thiophylidene benzhydrazide generated in the range from 35 to $-60 \mathrm{kcal} \mathrm{mol}^{-1}$, are presented in Figure 5. MEP plots calculated on the van der Waals surface and focusing on the negative isopotential surfaces might be used for describing the occurrence of the electronic conjugate effect in substituted benzene groups and the 5-nitro-heterocyclic ring.

In all MEPs determined, the results of the distribution of the most negative potential regions were demonstrated in red. These regions are located in the nitro group and oxygen of the carbonyl region of the molecule. The center of the structure presents the extended distribution of negative charges, as shown in light green, which becomes more negative (green color) as the potential becomes higher. The positive potential is located in the hydrogen atoms of the benzene group, the alpha carbon atom of the nitro group, and the nitrogen of the amidic portion of hydrazide (blue color). As shown in the posterior view of the chemical structure of the nitroheterocyclic compound, Figure 5 (1B and 2B), the clouds of negative MEP were not continuous in all the molecular set, showing the interruption in the bond located between the benzene and hydrazide group. Additionally, as illustrated in the front view of the molecule, the lower electronic density on the benzene group may be visualized by the less intense green color in comparison to the 5-nitro-heterocyclic ring.
The absence of conjugate resonance effect in the molecule might be a result of the broken coplanarity effect between hydrazide and benzene group.

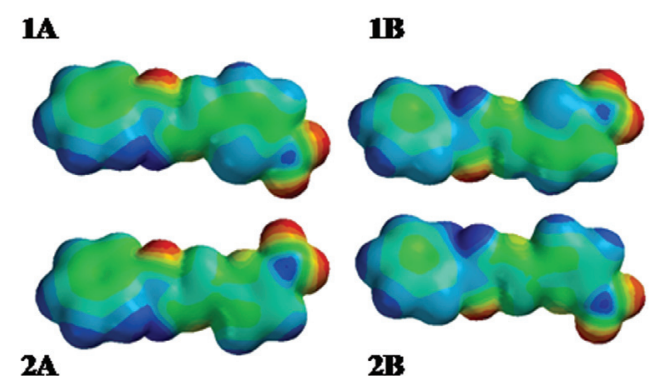

Figure 5. MEPs 3D calculated using AM1 isosurface $0.002 \mathrm{eV}$ for (1) 5-nitro-2-thiophylidene benzhydrazide, $(\mathrm{S}) \mathrm{H}$, and (2) 5-nitro-2furfurylidene benzhydrazide, $(\mathrm{O}) \mathrm{H}$. Above: (A) front view; (B) down posterior view, color range: -60.000 (red) to 35.000 (blue) $\mathrm{kcal} \mathrm{mol}^{-1}$.

Analyses of frontier orbitals were carried out using the thermodynamic energy values and maps of HOMO and LUMO distribution. The HOMO maps obtained from 5-nitro-2-thiophylidene benzhydrazide (1A) and 5-nitro2-firfurylidene benzhydrazide (2A) are shown in Figure 6.

The analysis of the HOMO maps of two templates shows that the distribution energy is located in the hydrazide region of these molecules. For the common part of the molecules, 5-nitro-2-furfurylidene hydrazide and 5-nitro-2thiophylidene hydrazide derivatives showed similar results. However, when the furfurylidene and thiophylidene rings were evaluated, the HOMO energy clouds were observed only in the region located in the sulfur atom of the heterocyclic ring. This HOMO energy profile was similar to those obtained for all other nitro compounds. This observation should be attributed to the better electronic accommodation in $d$ energy orbital of the sulphur atom. ${ }^{32}$.

All compounds demonstrated different results when electron acceptor or donor functional groups were attached to the para position of the benzene rings. A well defined separation was evidenced in the distribution of HOMO in thiophylidene and furfurylidene derivatives. In the presence of acceptor groups attached to the substituted benzene, the HOMO energy was located mainly in the 5-nitro-2-thiophylidene or furfurylidene hydrazide, as already reported for the non-substituted compound. On the other hand, HOMO energy was observed in almost all regions of molecules which had electron donor groups attached to the benzene. In particular, the hydrazide region presents a lower intensity of the HOMO distribution coefficient which decreases towards the heterocyclic group. Only one compound, the 5-nitro-2-furfurylidene4-methylbenzhydrazide, demonstrated no HOMO energy sites in the benzene group. 
Use Figure 6 displays LUMO distribution for 5-nitro2-thiophylidene benzhydrazide (1B) and 5-nitro-2furfurylidene benzhydrazide (2B). The LUMO distribution is quite similar to that observed for HOMO in both non-substituted compounds, whereas the distribution energy is mainly concentrated at the hydrazide region. As mentioned before, differences were found in molecules of nitro-thiophylidene and nitro-furfurylidene derivatives for HOMO models when they presented electron acceptor or donor functional groups attached to the para position of the benzene ring. In compounds that present the electron acceptor groups, these are distributed almost over the whole molecules with a lower intensity of energy registered for the LUMO distribution region in the benzene ring. In derivatives containing electron donor groups, the LUMO distribution regions are almost evenly distributed in the 5-nitro-2-heterocyclic hydrazide portion of the molecules. The difference between the HOMO and LUMO distributions around the molecules is a property related to the molecular reactivity, which can affect the nitro reduction. The differences of orbital energy may be suggested for future studies as an important factor in the set of interactions that results in anti-T.cruzi activity. This fact was already reported by Aguirre et al (2004) for a set of nitro-heterocyclic compounds with anti-T. cruzi activity. ${ }^{7}$ However, HOMO and LUMO did not show influence on the redox potential of the nitro group attached to the heterocyclic ring for this series of compounds.

The HOMO and LUMO distributions allow the determination of hardness, which is an important property referring to the reactivity of molecules. A hard molecule is defined as having a large energy gap between HOMO and LUMO eigenvalues [(LUMO + HOMO)/2]. The hardness characterizes the resistance of the electron cloud of a given molecule to suffer changes in a chemical reaction or interaction with a biological target. This property also describes the difficulty of the molecule to shift the spatial charge distribution..$^{21,33-35}$ The 5-nitro-2-thiophydene benzhydrazides show a small range in molecular hardness values determined for this class of compounds. The lowest value obtained was $-3.92 \mathrm{eV}$ from a methoxyl derivative, and the highest value was $-4.01 \mathrm{eV}$, obtained from the trifluoromethyl derivative.

For 5-nitro-2-furfurylidene benzhydrazides, however, hardness shows a larger range, in which the trimethylamine derivative shows the lowest value $(-3.79 \mathrm{eV})$ and the trifluoromethyl derivative shows the highest hardness $(-4.04 \mathrm{eV})$. Although there is a greater variation of molecular hardness in the 5-nitro-2-furfurylidene derivatives, the close values of this physicochemical property do not allow the identification of which compound is the most reactive one.

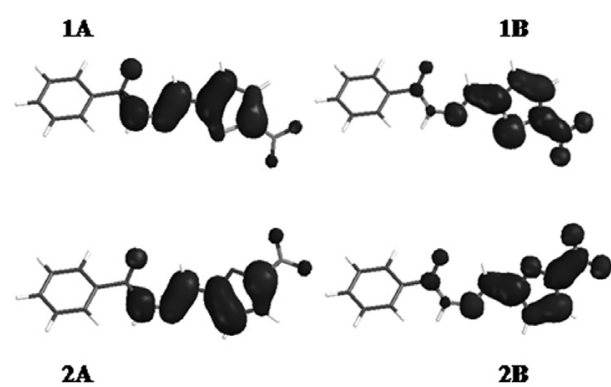

Figure 6. HOMO (A) and LUMO (B) 3D distributions calculated using AM1 method with isosurface $0.032 \mathrm{eV}$ to (1) 5-nitro-2-thiophylidene benzhydrazide and (2) 5-nitro-2-furfurylidene benzhydrazide.

The electrostatic potential charges $(Q)$ for all atoms were determined by analyses of electrostatic potential maps. These charges, based on the calculation of a punctual atomic charge defined around the molecules, ${ }^{25-27}$ provide information about the reactivity or the interaction of these molecules with the bioactive enzymatic site. The charges of the substituted carbon $(\mathrm{C} 1)$ located at benzene ring $\left(Q_{C l}\right)$, and carbon of the five heterocyclic ring members (C14) and the neighbor of nitro group $\left(Q_{C 14}\right)$ were calculated for all nitro-heterocyclic compounds and are shown in Table 2. These atom charges were determined because these atoms present a higher possibility of suffering influence from the different groups attached to them. The results obtained from calculating the electrostatic potential charges at $\mathrm{C}_{14}$ atom, however, show no great differences among all eigenvalues determined. For large range of values, -0.17 to 0.62 charges were observed for the calculated $\mathrm{C}_{1}$ atoms, which reflects the presence of acceptor or donor groups attached to the benzene ring. This variation might be used to plan new compounds with higher reactivity and to better understand the biological interactions present in anti-T.cruzi activity.

\section{Voltammetry}

Cyclic voltammetry was used as the electrochemical technique to determine the $\mathrm{Ar}-\mathrm{NO}_{2} / \mathrm{Ar}-\mathrm{NO}_{2}{ }^{--}$redox potential $\left(\mathrm{E}^{\circ}\right)$, which corresponds to $\left(\mathrm{E}_{\mathrm{pal}}+\mathrm{E}_{\mathrm{pcl}} / 2\right)$. $\mathrm{E}_{\mathrm{cpI}}$ and $\mathrm{E}_{\text {apI }}$ are the reduction and oxidation peaks correspondent to the production of $\mathrm{Ar}-\mathrm{NO}_{2}^{--}$from $\mathrm{Ar}-\mathrm{NO}_{2}$ and, $\mathrm{Ar}-\mathrm{NO}_{2}$ from Ar- $\mathrm{NO}_{2}{ }^{-}$, respectively. Data presented on Figure 7a show the cyclic voltammograms recorded in dimethylsulfoxide containing $5.0 \times 10^{-4} \mathrm{~mol} \mathrm{~L}^{-1}$ of 5-nitro-2-thiophylidene benzhydrazide and $0.1 \mathrm{~mol} \mathrm{~L}^{-1} \mathrm{Bu}_{4} \mathrm{NH}_{4} \mathrm{BF}_{4}$ as a supporting electrolyte. Increasing scan rate, $\Delta \mathrm{Ep}\left(\mathrm{E}_{\mathrm{pal}}-\mathrm{E}_{\mathrm{pcc}}\right)$ shifted from 0.067 to $0.075 \mathrm{~V}$ while $\mathrm{i}_{\text {ap1 }} / \mathrm{i}_{\mathrm{cpl}}$ ratios were near the unity, characteristics which can be attributed to one electron, reversible or quasi-reversible charge transfer reaction. However, it seems that the electrochemical process is partially controlled by adsorption (Figure 7b), 
which difficult the experimental determination of the electrons number using the chronotechniques or the Randles-Sevcik equation. ${ }^{36} \mathrm{In}$ fact, $\Delta \mathrm{Ep}$ should be null for an electrochemical process which occurs from the species in the adsorbed state. Data presented on Figure $7 \mathrm{a}$ and linear Ip $-v$ plot are indicative of mixed electrochemical process at the electrode surface. As can be observed from data presented on Figure $7 \mathrm{a}, \mathrm{i}_{\mathrm{apl}} / \mathrm{i}_{\mathrm{cpl}}$ ratio decreased at scan rate high than $500 \mathrm{mV} \mathrm{s}^{-1}$, and therefore the validity of $\mathrm{E}^{\circ}$ values is restricted to this small scan rate range.
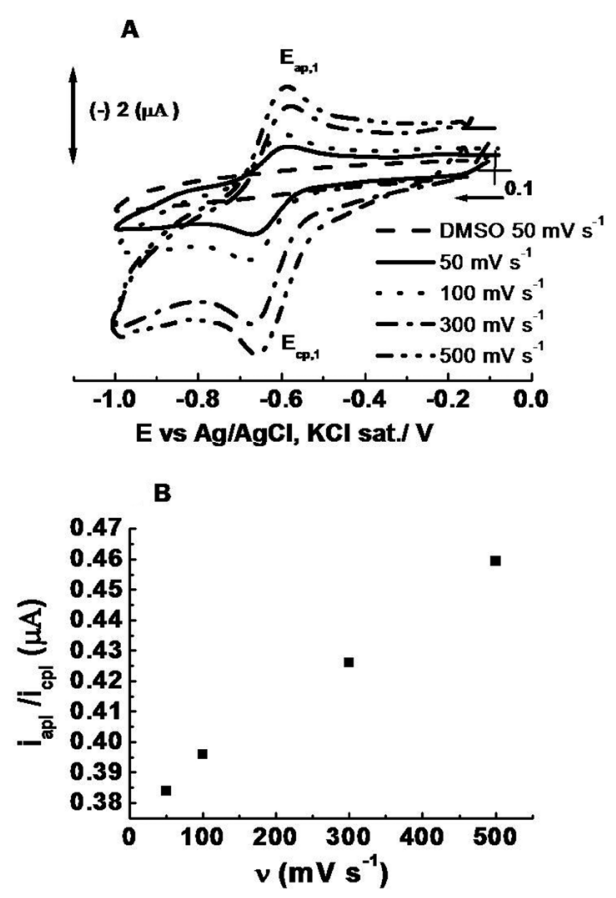

Figure 7. Cyclic voltammograms (A) and Plot of $\mathrm{i}_{\text {apl }} / \mathrm{i}_{\text {cpl }} v s . v$ (B) recorded at GCE in aprotic medium: A) $100 \mathrm{mV} \mathrm{s}^{-1}$, B) $300 \mathrm{mV} \mathrm{s}^{-1}$, C) $\left.700 \mathrm{mV} \mathrm{s}^{-1}, \mathrm{D}\right) 1000 \mathrm{mV} \mathrm{s}^{-1}, \mathrm{E}_{\text {initial }}=-0.05 \mathrm{~V}, \mathrm{E}_{\lambda}=-1.0 \mathrm{~V}$ and $\mathrm{E}_{\text {final }}=-0.15 \mathrm{~V} \mathrm{~A}$ ) $5.0 \times 10^{-4} \mathrm{~mol} \mathrm{~L}^{-1}$ of 5-nitro-2-thiophylidene benzhydrazide.

Only small differences in the redox potential values were obtained among all the nitro compounds studied (Table 2). $\mathrm{E}^{\circ}$ of the 5-nitro-2-thiophylidene benzhydrazides studied shifted in the range of -0.58 to $-0.64 \mathrm{~V}$ as compared with $\mathrm{E}^{\circ}$ of the 5-nitro-2-furfurylidene benzhydrazides, which $\mathrm{E}^{\mathrm{o}}$ shifted in the range of -0.50 to $-0.70 \mathrm{~V}$. No significant differences were observed between the $\mathrm{E}^{\mathrm{o}}$ values found in this paper and those, obtained in aprotic media for different analogs of this classes of compounds. ${ }^{37,38}$ According Figure $7 \mathrm{a}, \Delta$ Ep shifted in the range of $67-75 \mathrm{mV}$ and $\mathrm{I}_{\mathrm{apl}} / \mathrm{I}_{\mathrm{cpl}}$ of the $\mathrm{Ar}-\mathrm{NO}_{2} / \mathrm{Ar}^{-\mathrm{NO}_{2}}{ }^{--}$ redox couple did not shift from unity increasing the scan rate in the range of $50 \leq v \leq 500 \mathrm{mV} \mathrm{s}^{-1}$, which is an indicative that the electrochemical process corresponds to one electron transfer on the electrode/solution interface.
The re-oxidation of $\mathrm{Ar}^{-\mathrm{NO}_{2}}{ }^{-}$free radical at low scan rate $\left(50 \mathrm{mV} \mathrm{s}^{-1}\right)$, could be related to the adsorption phenomena at the electrode surface.

\section{Evaluation of the influence of physicochemical properties} on redox potential

No PLS models obtained were statistically adequate to indicate which structural property would be important for nitro compound reduction. In addition, no correlation was observed between the theoretical physicochemical properties and the redox potential of all nitro compounds, which suggests that the considered properties do not exert influence on the electrochemical reduction of this class of nitrocompounds. It means that, independently on the substituent groups attached at $p$-position of the benzene ring, there is no influence from these groups on the redox potential. This lack of statistical correlation might be explained by the absence of the coplanarity feature between

Table 1. Geometric properties for 5-nitro-2-heterocyclic benzhydrazides para-substituted generated by single point calculations using AM1 semiempirical method

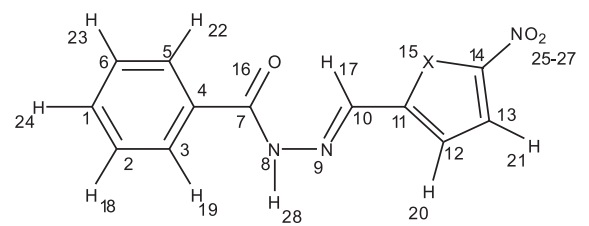

\begin{tabular}{lccccc}
\hline X $=$ S, O) & \multicolumn{2}{c}{ Dihedral angles (degrees) } & \multicolumn{2}{c}{ Geometric } \\
Substitution & O16-C7- & N8-C7- & C10-N9- & MV & ID \\
in C1 & C4-C3 & C4-C5 & N8-C7 & $(\ddot{A})^{*}$ & $(\hat{A})^{* *}$ \\
\hline (S) H & 38.61 & 40.85 & 2.62 & 250.81 & 14.30 \\
(S) CH3 & 38.05 & 39.74 & 2.53 & 258.99 & 15.21 \\
(S) F & 38.75 & 41.00 & 3.13 & 255.71 & 14.37 \\
(S) CF3 & 40.71 & 42.87 & 3.15 & 283.70 & 15.54 \\
(S) OCH3 & 35.88 & 38.35 & 3.23 & 278.15 & 16.45 \\
(S) N(CH3)2 & 34.01 & 36.55 & 3.68 & 300.32 & 16.59 \\
(S) NH2 & 34.86 & 37.28 & 3.86 & 261.08 & 15.22 \\
(S) OH & 36.03 & 38.51 & 3.34 & 257.99 & 15.04 \\
(O) H & 38.39 & 41.29 & 2.18 & 243.51 & 14.12 \\
(O) CH3 & 38.11 & 40.48 & 2.34 & 261.69 & 14.96 \\
(O) F & 37.79 & 40.30 & 2.91 & 248.40 & 14.37 \\
(O) CF3 & 40.80 & 43.80 & 2.69 & 276.41 & 15.20 \\
(O) OCH3 & 35.62 & 38.26 & 2.71 & 270.85 & 16.23 \\
(O) N(CH3)2 & 35.59 & 36.31 & 2.91 & 293.00 & 16.32 \\
(O) NH2 & 34.71 & 37.25 & 3.43 & 253.78 & 14.94 \\
(O) OH & 35.78 & 38.43 & 2.49 & 250.69 & 14.78 \\
\hline
\end{tabular}

* Molecular volume;

** Interatomic distances. 
Table 2. Energy of formation, $\mathrm{E}_{\mathrm{HOMO}}, \mathrm{E}_{\mathrm{LUMO}}$, and molecular hardness eigenvalues obtained from single point calculations using AM1 semiempirical method

\begin{tabular}{|c|c|c|c|c|c|c|c|}
\hline & $\begin{array}{c}\Delta \mathrm{Hf} \\
\text { (kcal mol-1) }\end{array}$ & $\begin{array}{c}\text { EHOMO } \\
(\mathrm{eV})\end{array}$ & $\begin{array}{l}\text { ELUMO } \\
(\mathrm{eV})\end{array}$ & $\begin{array}{l}\mathrm{MH}^{*} \\
(\mathrm{eV})\end{array}$ & QC1 & QC14 & $\begin{array}{l}\text { Eo } \\
(\mathrm{V})\end{array}$ \\
\hline (S) $\mathrm{H}$ & 63.9093 & -9.42 & -1.53 & -3.94 & -0.02 & -0.25 & -0.63 \\
\hline (S) $\mathrm{CH} 3$ & 56.0112 & -9.38 & -1.51 & -3.93 & 0.21 & -0.28 & -0.58 \\
\hline (S) F & 19.2570 & -9.50 & -1.59 & -3.93 & 0.40 & -0.24 & -0.62 \\
\hline (S) $\mathrm{CF} 3$ & -90.3166 & -9.63 & -1.69 & -4.01 & 0.46 & -0.25 & -0.61 \\
\hline (S) $\mathrm{OCH} 3$ & 14.9156 & -9.35 & -1.50 & -3.92 & 0.48 & -0.24 & -0.63 \\
\hline (S) $\mathrm{N}(\mathrm{CH} 3) 2$ & 61.0253 & -8.81 & -1.43 & -3.68 & 0.46 & -0.25 & -0.62 \\
\hline (S) NH2 & 60.9041 & -9.08 & -1.45 & -3.81 & 0.62 & -0.24 & -0.64 \\
\hline (S) $\mathrm{OH}$ & 50.1645 & -9.39 & -1.53 & -3.93 & 0.47 & -0.24 & - \\
\hline (O) $\mathrm{H}$ & 50.1645 & -9.41 & -1.34 & -4.03 & 0.01 & -0.03 & -0.68 \\
\hline (O) $\mathrm{CH} 3$ & 42.2549 & -9.38 & -1.33 & -4.02 & 0.20 & 0.00 & -0.68 \\
\hline (O) F & 5.5323 & -9.49 & -1.41 & -4.03 & 0.39 & 0.01 & -0.68 \\
\hline (O) $\mathrm{CF} 3$ & -103.9883 & -9.62 & -1.53 & -4.04 & -0.17 & -0.03 & -0.50 \\
\hline (O) $\mathrm{OCH} 3$ & 50.1645 & -8.82 & -1.32 & -4.01 & 0.45 & -0.05 & -0.68 \\
\hline (O) $\mathrm{N}(\mathrm{CH} 3) 2$ & 57.4738 & -9.35 & -1.32 & -3.79 & 0.46 & 0.00 & -0.68 \\
\hline (O) $\mathrm{NH} 2$ & 47.0931 & -9.10 & -1.26 & -3.92 & 0.62 & -0.01 & -0.68 \\
\hline (O) $\mathrm{OH}$ & 5.4690 & -9.39 & -1.34 & -4.02 & 0.47 & 0.00 & -0.70 \\
\hline
\end{tabular}

* Molecular hardness.

the benzene substituted groups and the nitro group of the heterocyclic ring. The structures $1 \mathrm{~B}$ and $2 \mathrm{~B}$ showed in Figure 5 corroborate these results, where lower electronic density may be observed between the two cited molecular regions. When the two classes, 5-nitro-2-thiophylidene benzhydrazides or 5-nitro-2-furfurylidene benzhydrazides were separately considered, the very small differences among the $\mathrm{E}^{\mathrm{o}}$ values obtained suggest that the radicals generated are close one to another, and these results might not be used to explain some specific differences of expected reactivity. These values can not be used as the only way to explain some biological activity to be investigated in the future. The results obtained should be considered in drug design studies, since the nitro group potential reduction, and therefore the nitro radical generation, will not be influenced in large molecules where the resonance effect is absent.

\section{Conclusions}

The conformational analysis allows us determining the conformations for all the nitro-heterocyclic compounds and their conformations are in agreement with the reaction phase studied. The models obtained showed the occurrence of common geometric features such as the breaking of the coplanarity in the benzene substituted ring.

In addition, analyses of MEPs indicate that the electronic effect of the substituted functional groups does not exert influence on the conjugate electronic effect observed in the 5-nitro-heterocyclic-hydrazide region from molecules of 5-nitro-2-thiophylidene benzhydrazides and 5-nitro-2-furfurylidene benzhydrazides. The HOMO and LUMO distribution regions and the differences observed between them appear to establish the interesting factors involved in molecular reactivity, and could be used in prospective design of compounds with anti-T. cruzi activity. The evaluation of stereoelectronic properties, such as HOMO, LUMO, chemical hardness, and electrostatic potential charge at $Q_{C 14}$, calculated from the gaseous phase show small differences in the values for all compounds studied. For charges at $Q_{C l}$ and energy of formation were observed the good variation among all values determined, but no correlation was observed among these properties and the redox potential. Moreover, all theoretical properties determined did not exert influence on the redox potential values obtained from nitro compounds reduction. These properties, in spite of not being important for nitro-heterocyclic reduction, might be used in further studies involving potential anti- $T$. cruzi agents as well as for the development of bioactive 5-nitro-heterocyclic compounds.

\section{Acknowledgments}

F. R. Paula thanks CNPq and G. H. G. Trossini thanks FAPESP for Fellowships. All authors also thanks CNPq, and FAPESP (project number 01/01192-3) for financial support. 


\section{References}

1. The World Health Organization, WHO publications, http:// www,who.int/ctd/chagasdts/html, 2000, accessed in September 2008.

2. Coura, J. R.; Castro, S. L.; Mem. Inst. Oswaldo Cruz 2002, 97, 3.

3. Cerecetto, H.; Gonzáles, M.; Curr. Top. Med. Chem. 2002, 2 , 1185.

4. Paulino, M.; Iribarne, F.; Hansz, M.; Veja, M.; Seoane, G.; Cerecetto, H.; Di Maio, R.; Caracelli, I.; Zukerman-Schpector, J.; Olea, C.; Stoppani, A. O. M.; Berriman, M.; Fairlamb, A. H.; Tapia, O.; J. Mol. Struct. (THEOCHEM) 2002, 584, 95.

5. Pozas, R.; Carballo, J.; Castro, C.; Rubio, J.; Bioorg. Med. Chem. Lett. 2005, 15, 1417.

6. Blumenstiel, K.; Schöneck, R.; Yardley, V.; Croft, S. L.; KrauftSiegel, R. L.; Biochem. Pharmacol. 1999, 58, 1791.

7. Aguirre, G.; Boiani, L.; Cerecetto, H.; Fernández, M.; González, M.; Denicola, A.; Otero, L.; Gambino, D.; Rigol, C.; Olea-Azar, C.; Faundez, M.; Bioorg. Med. Chem. 2004, 12, 4885.

8. Henderson, G. B.; Ulrich, P.; Fairlamb, A.H.; Rosenberg, I.; Pereira, M.; Sela, M.; Cerami, A.; Proc. Nat. Acad. Sci. USA 1988, 85, 5374.

9. Viodé, C.; Bettache, N.; Cenas, N.; Krauth-Siegel, R. L.; Chauviére, G.; Bakalara, N.; Perie, J.; Biochem. Pharmac. 1999, $57,549$.

10. Edwards, D. I.; J. Antimicrob. Chemother. 1993, 31, 09.

11. Tavares, L. C.; Penna, T. V. C.; Amaral, A. T.; Boll. Chim. Farm. 1997, 136, 244.

12. Tavares, L. C.; Chisté, J. J.; Santos, M. G. B.; Penna, T. V. C.; Boll. Chim. Farm. 1999, 138, 432.

13. Rando, D. G.; Sato, D. N.; Siqueira, L.; Malvezzi, A.; Leite, C. Q. F.; Amaral, A. T.; Ferreira, E. I.; Tavares, L. C.; Bioorg. Med. Chem. 2002, 10, 557.

14. Paula, F. R.; Doria, S. J.; Almeida, L. V.; Pasqualoto, K. F. M.; Tavares, L. C.; Bioorg. Med. Chem. 2009, 17, 2673.

15. Rozenski, J.; De Raunter, C. J.; Verplanken, H.; Quant. Struct.Act. Relat. 1995, 14, 134.

16. Thakur, M.; Thakur, A.; Balasubramanian, K.; J. Chem. Inf. Model. 2006, 46, 103.

17. Rigol, C.; Olea-Azar, C.; Mendizábal, F.; Briones, R.; Cerecetto, H.; González, M.; J. Mol. Struct. (THEOCHEM) 2006, 770, 125.

18. Ifa, D. R.; Rodrigues, C. R.; De Alencastro, R. B.; Fraga, C. A. M.; Barreiro, E. J.; J. Mol. Struct. (THEOCHEM) 2000, 505, 11.
19. Figueiredo, J. M.; Câmara, C. de A.; Amarante, E. G.; Miranda, A. L. P.; Santos, F. M.; Rodrigues, C. R.; Fraga, C. A. M.; Barreiro, E. J.; Bioorg. Med. Chem. 2000, 8, 2243.

20. Bhattacharjee, A. K.; Skanchy, D. J.; Jennings, B.; Hudson, J T. H.; Brendle, J.; Werbonvetz, K. A.; Bioorg. Med. Chem. 2002, 10, 1979.

21. Anadan, K.; Kolandaivel, P.; Kumaresan, R.; Gowenlock, B. G.; J. Mol. Struct. (THEOCHEM) 2003, 639, 213.

22. Bhattacharjee, A. K.; Karle, J. M.; J. Med. Chem. 1996, 39, 4622.

23. Hehre, W. J.; Hunag, W. W.; Klunzinger, P. E.; Deppmeier, B. J.; Driessen, A. J.; Spartan 4.0: User's guide, Wavefunction, Inc., Irvine, CA, 1998.

24. Dewar, M. J. S.; Zoebisch, E. G.; Healy, E. F.; Stewart, J. J. P.; J. Am. Chem. Soc. 1985, 107, 3902.

25. Chirlian, L. E.; Fracl, M. M.; J. Comput. Chem. 1987, 8, 894.

26. Guadagnini, P. H.; Bruns, R. E.; De Souza, A. A.; Quim. Nova 1996, 19, 148.

27. Cramer, C. J. In Essential of Computational Chemistry: Theory and Models, $2^{\text {nd }}$ ed., John Wiley \& Sons: New York, 2002, p. 275.

28. Cramer, C. J.; Truhlar, D. G.; Science 1992, 256, 213.

29. Dixon, R. W.; Leonard, J. M.; Hehre, W. J. A.; Isr. J. Chem. 1993, 33, 427.

30. Young, D. C. In Solvation: Computational Chemistry. In A Practical Guide for Applying Techniques to Real-Word Problems, John Wiley \& Sons: New York, 2001, p. 206.

31. Pniewska, B.; Jnuchowski, M.; Pol. J. Chem. 1999, 72, 2629.

32. Doreto, R. L.; Laks, B.; J. Chem. Phys. 2002, 117, 5437.

33. Freitas, M. P.; Tormena, C. F.; Luízar, C.; Ferreira, M. M. C.; Rittner, R.; J. Mol. Struct. (THEOCHEM) 2002, 618, 219.

34. Pearson, R. G.; J. Chem. Educ. 1987, 64, 561.

35. Anadan, K.; Kolandaivel, P.; Kumaresan, R.; J. Mol. Struct. (THEOCHEM) 2004, 686, 83.

36. Julião, M. S. S.; Almeida, E. C.; Scalea, M. A. L.; Ferreira, N. G.; Compton, R. G.; Serrano, S. H. P.; Electroanalysis 2005, 18, 269.

37. Bollo, S.; Núñes-Vergara, L. J.; Martinez, C.; Chauviére, G.; Périé, J.; Squella, J. A.; Electroanalysis 2003, 15, 9.

38. Stradins, J.; Gavars, R.; Baumane, L.; Electrochim. Acta 1983, 28,495 .

Received: December 16, 2008

Web Release Date: January 28, 2010

FAPESP helped in meeting the publication costs of this article. 